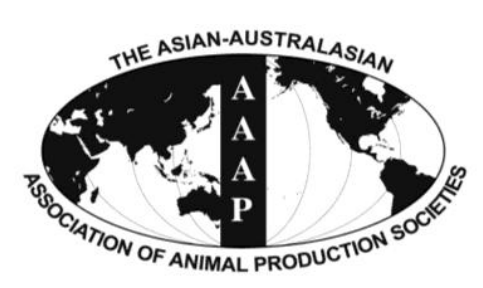

\title{
Assessment of Genetic Diversity, Relationships and Structure among Korean Native Cattle Breeds Using Microsatellite Markers
}

\author{
Sangwon Suh, Young-Sin Kim, Chang-Yeon Cho, Mi-Jeong Byun, Seong-Bok Choi, Yeoung-Gyu Ko, \\ Chang Woo Lee ${ }^{1}$, Kyoung-Sub Jung ${ }^{2}$, Kyoung Hun Bae ${ }^{3}$, and Jae-Hwan Kim* \\ Animal Genetic Resources Station, National Institute of Animal Science, RDA, Namwon 590-832, Korea
}

\begin{abstract}
Four Korean native cattle (KNC) breeds-Hanwoo, Chikso, Heugu, and Jeju black-are entered in the Domestic Animal Diversity Information System of the United Nations Food and Agriculture Organization (FAO). The objective of this study was to assess the genetic diversity, phylogenetic relationships and population structure of these KNC breeds $(\mathrm{n}=120)$ and exotic breeds (Holstein and Charolais, $\mathrm{n}=56$ ). Thirty microsatellite loci recommended by the International Society for Animal Genetics/FAO were genotyped. These genotypes were used to determine the allele frequencies, allelic richness, heterozygosity and polymorphism information content per locus and breed. Genetic diversity was lower in Heugu and Jeju black breeds. Phylogenetic analysis, Factorial Correspondence Analysis and genetic clustering grouped each breed in its own cluster, which supported the genetic uniqueness of the KNC breeds. These results will be useful for conservation and management of KNC breeds as animal genetic resources. (Key Words: Korean Native Cattle Breeds, Microsatellite, Genetic Diversity, Relationships)
\end{abstract}

\section{INTRODUCTION}

Korean cattle have existed in the Korean Peninsula for at least 2000 years (Kim and Lee, 2000). A mural in a tomb dating from the Kokuryo Age (“Anak-3-hobun”, A.D. 357) depicts three cattle heads that differ in coat color (brown, brindle and black) (Na, 2008). These ancient animals are thought to be the origin of the native cattle breeds existing in Korea. Four Korean native cattle (KNC) breeds have been recently documented in the Domestic Animal Diversity Information System of the United Nations Food and Agriculture Organization (FAO; http://dad.fao.org/) Hanwoo (HW), Chikso (CS), Heugu (HU), and Jeju black

\footnotetext{
* Corresponding Author: Jae-Hwan Kim. Tel: +82-636203522, Fax: +82-636203590, E-mail: jkim3892@korea.kr

${ }^{1}$ Gangwon Provincial Livestock Research Center, Hoengseong, Gangwon 225-831, Korea.

2 Chungbuk Institute of Livestock and Veterinary Research, Cheongwon, Chungbuk 363-931, Korea.

${ }^{3}$ Jeju Special Self-Governing Province Livestock Promotion, Jeju 690-802, Korea.

Submitted Jun. 12, 2014; Revised Aug. 27, 2014; Accepted Sept. 23, 2014
}

(JB). These breeds are classified based on different coat colors (HU and JB, black; HW, brown; CS, brindle) (Figure 1) and geographical distribution (HW is widely distributed in Korea, JB only on Jeju Island and HU and CS on the Korean peninsula, except Jeju Island).

Beginning in the 1960's, the Korean government embarked on a strategy aimed at enhancing the performance and genetic ability of HW. The program was successful and now HW is one of the superior commercial livestock breeds in Korea. The other breeds had been except from this governmental plan and their existence became precarious (MAF, 2004). In response the government committed to the conservation and proliferation of JB, HU, and CS, given their recognition as valuable genetic resources for development of new beef cattle different from HW.

High polymorphic nuclear markers are now commonly used in the evaluation of genetic diversity, phylogenetic relationship and population structure within and among livestock breeds (Groeneveld et al., 2010). Microsatellite analyses have provided useful genetic information for European (Maudet et al., 2002; Wiener et al., 2004; Padilla et al., 2009), African (Dadi et al., 2008), mid-South 

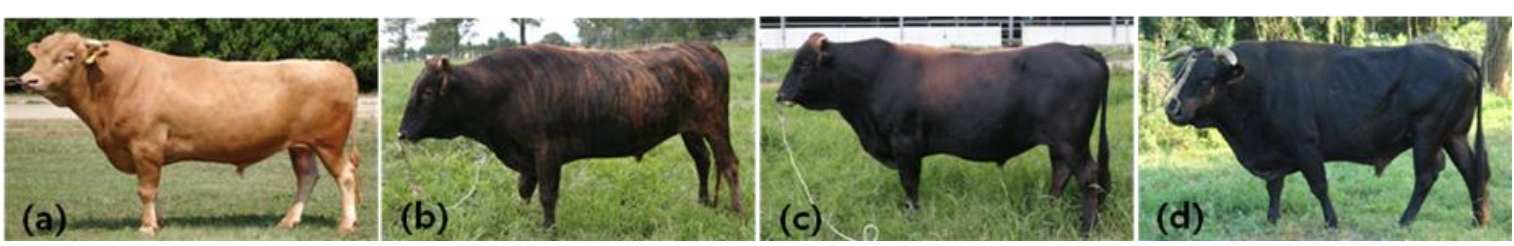

Figure 1. Different coat color phenotypes of the Korean native cattle breed; (a) Hanwoo, (b) Chikso, (c) Heugu, (d) Jeju black.

American (Egito et al., 2007; Acosta et al., 2013) and Asian cattle breeds (Zhang et al., 2007; Pham et al., 2013). In Korea, several studies have evaluated the genetic diversity and genetic relationship of HW compared with other breeds (Kim et al., 2002; Choi et al., 2012). However, little genetic characterization of JB, HU, and CS has been done.

The aims of the present study were to evaluate the extent of the genetic diversity of $\mathrm{KNC}$ breeds, and to establish the relationships between the four Korean native and exotic cattle breeds using 30 microsatellite markers.

\section{MATERIALS AND METHODS}

\section{Blood sampling and DNA extraction}

Blood from $30 \mathrm{CS}$ individuals were sampled from two local institutes (Gangwon Provincial Livestock Research Center and Chungbuk Veterinary Service Center). Blood was collected from HU $(n=30)$ and JB $(n=30)$ from Chungbuk Veterinary Service Center and Jeju Special SelfGoverning Provincial Livestock Institute, respectively. Blood samples of these three breeds were randomly collected, while avoiding parent-offspring or sib pairs where possible according to pedigree information of each institute. The HW $(\mathrm{n}=30)$ was additionally sampled for blood from 11 farms (1 to 7) in Yeongju City.

Genomic DNA from blood samples was extracted using the DNeasy Blood Kit (Qiagen, Germany) following the manufacturer's procedure. Genomic DNA of two exotic breeds, Holstein $(\mathrm{n}=30)$ and Charolais $(\mathrm{n}=26)$ was obtained from the Animal Genetic Resources Station, National Institute of Animal Science, Rural Development Administration.

\section{Polymerase chain reaction amplification and} microsatellite genotyping

Thirty microsatellite markers (BM1818, BM1824, BM2113, CSRM60, CSSM66, ETH3, ETH10, ETH152, ETH185, ETH225, HAUT24, HAUT27, HEL1, HEL5, HEL9, HEL13, ILSTS005, ILSTS006, INRA005, INRA023, INRA032, INRA035, INRA037, INRA063, MM12, SPS115, TGLA53, TGLA122, TGLA126, and TGLA227) were analyzed to estimate various parameters of genetic diversity. Microsatellites were amplified in multiplexes (3 to 4 co-amplified loci), with the exception of ETH185. Polymerase chain reaction amplification was performed in a
$15 \mu \mathrm{L}$ reaction mixture, which contained $1.5 \mathrm{mM} \mathrm{MgCl}_{2}, 1$ $\mathrm{U}$ of AmpliTaq Gold (Applied Biosystems, Foster, CA, USA), 3-10 pmol of each forward (labeled with a fluorescent-colored dye) and reverse primer and approximately $10 \mathrm{ng}$ genomic DNA as a template.

The PCR amplification comprised an initial denaturation at $95^{\circ} \mathrm{C}$ for $15 \mathrm{~min}$, followed by 35 cycles of denaturation at $95^{\circ} \mathrm{C}$ for $30 \mathrm{~s}$, annealing at $55^{\circ} \mathrm{C}$ to $63^{\circ} \mathrm{C}$ (respective optimal annealing temperature) for $90 \mathrm{~s}$, extension of starters at $72^{\circ} \mathrm{C}$ for $90 \mathrm{~s}$ and a final extension of starters at $72^{\circ} \mathrm{C}$ for $40 \mathrm{~min}$, using the GeneAmp PCR System 9700 (Applied Biosystems). Electrophoresis was carried out using an ABI 3130xl Genetic Analyzer (Applied Biosystems). Allele sizes of each microsatellite were determined using GeneMapper ver. 4.0 (Applied Biosystems). The formulated allele data was used for statistical analyses.

\section{Statistical analyses}

Cervus ver. 3.0.3 (Kalinowski et al., 2007) was used to estimate allele frequencies, total number of alleles (TNA), mean observed $\left(\mathrm{H}_{\mathrm{Obs}}\right)$ and expected $\left(\mathrm{H}_{\text {Exp }}\right)$ heterozygosities ad mean polymorphism information content (PIC) per locus and breed. Allelic richness $\left(A_{R}\right)$ for each breed was calculated to correct distortion by sample size difference using FSTAT ver. 2.9.3.2. (Goudet, 2002). The $D_{A}$ genetic distance (Nei et al., 1983) was calculated with MSA (Dieringer and Schlötterer, 2003). The three dimensions of a multivariate factorial correspondence analysis (FCA) were computed using GENETIX ver. 4.05 (Belkhir et al., 2004) from allele doses for each individual. The FCA was carried out from all animals and for the 30 loci. Genetic structure and the degree of admixture of $\mathrm{KNC}$ breeds were investigated using the Bayesian clustering procedure of STRUCTURE ver. 2.3 (Pritchard et al., 2000). Fifty independent runs were performed for each $K$ between 2 and 10 , with a burn-in period of 50,000 iterations followed by 100,000 iterations of the Markov chain Monte Carlo algorithm. To identify the most probable groups $(K)$ that best fit the data, we used the STRUCTURE HARVESTER (Earl and von Holdt, 2012), which implements the Evanno method (Evanno et al., 2005). The program CLUMPP ver. 1.1 (Jakobsson and Rosenberg, 2007) was used to align the 50 repetitions of each $K$. The CLUMPP out files were visualized using DISTRUCT ver. 1.1 (Rosenberg, 2004). 


\section{RESULTS AND DISCUSSION}

\section{Microsatellite polymorphism}

Allele ranges, number of alleles, heterozygosity and PIC per locus are summarized in Table 1. A total of 276 alleles were detected at 30 microsatellite loci across four $\mathrm{KNC}$ breeds. The TNA per locus ranged from 4 (ILSTS005) to 17 (TGLA122), with a mean of $9.20 \pm 0.58$ alleles. The mean of $\mathrm{H}_{\text {Exp }}$ across loci was $0.733 \pm 0.018$, with estimates per locus ranging from 0.473 (ILSTS005) to 0.893 (TGLA53). For $\mathrm{H}_{\mathrm{Obs}}$, the mean for all loci was $0.667 \pm 0.028$, and the range was between 0.174 (INRA035) and 0.855 (CSRM60).

The 30 microsatellite markers used were recommended from by International Society for Animal Genetics/FAO (Hoffmann et al., 2004). Most of the loci were highly informative (PIC>0.5), with the exception of ILSTS005 (0.375) and HEL13 (0.413). Similarly, ILSTS005 and HEL13 have been reported to be the relatively low informative markers (Padilla et al., 2009). According to Botstein et al. (1980), PIC of $>0.5$ indicates a highly informative locus for chromosomal mapping and genetic diversity. Therefore, most microsatellite marker sets are highly informative and useful for evaluation of genetic diversity and population structure in $\mathrm{KNC}$ breeds.

\section{Genetic diversity across breeds}

The various indices of genetic diversity across the four KNC breeds are shown in Table 2. The mean number of alleles and $A_{R}$ ranged from $4.73 \pm 0.32$ (HU) to $6.97 \pm 0.41$ $(\mathrm{HW})$ and from $4.39 \pm 0.28(\mathrm{HU})$ to $6.42 \pm 0.37(\mathrm{HW})$, respectively. The mean value of $\mathrm{H}_{\operatorname{Exp}}$ was highest in HW (0.713) and lowest in JB (0.604). The mean value of $\mathrm{H}_{\mathrm{Obs}}$ ranged from 0.613 (HU) to 0.683 (CS). Generally, the levels of genetic diversity of HW and CS breeds were higher than those of HU and JB. The difference of the levels of genetic diversity among Korean cattle breeds could be explained by population sizes and distribution region. Populations of HW and CS are relatively large (currently 3,000,000 animals) and medium-sized (currently 1,700 animals), respectively. These two breeds are widely distributed throughout Korea. On the other hand, $\mathrm{HU}$ and JB are numerically small populations, with 300 to 400 animals each. Moreover, JB are restricted in their distribution to Jeju Island. HU and JB
Table 1. Polymorphism of 30 microsatellite loci across the four Korean cattle breeds

\begin{tabular}{|c|c|c|c|c|c|}
\hline Locus & $\begin{array}{l}\text { Allele range } \\
\text { (bp) }\end{array}$ & TNA & $\mathrm{H}_{\text {Exp }}$ & $\mathrm{H}_{\mathrm{Obs}}$ & PIC \\
\hline BM1818 & $256-276$ & 10 & 0.647 & 0.529 & 0.578 \\
\hline BM1824 & $178-192$ & 8 & 0.725 & 0.597 & 0.692 \\
\hline BM2113 & $122-140$ & 10 & 0.715 & 0.692 & 0.671 \\
\hline CSRM60 & $85-105$ & 10 & 0.721 & 0.855 & 0.697 \\
\hline CSSM66 & $177-201$ & 12 & 0.867 & 0.817 & 0.849 \\
\hline ETH3 & $113-127$ & 7 & 0.743 & 0.750 & 0.701 \\
\hline ETH10 & $207-225$ & 10 & 0.677 & 0.658 & 0.636 \\
\hline ETH152 & $193-203$ & 6 & 0.661 & 0.588 & 0.612 \\
\hline ETH185 & $227-245$ & 9 & 0.804 & 0.724 & 0.772 \\
\hline ETH225 & $139-157$ & 8 & 0.769 & 0.712 & 0.733 \\
\hline HAUT24 & $106-128$ & 10 & 0.760 & 0.678 & 0.719 \\
\hline HAUT27 & $140-156$ & 9 & 0.614 & 0.602 & 0.535 \\
\hline HEL1 & $102-112$ & 5 & 0.737 & 0.742 & 0.690 \\
\hline HEL5 & $142-168$ & 11 & 0.859 & 0.786 & 0.839 \\
\hline HEL9 & $143-169$ & 10 & 0.732 & 0.669 & 0.699 \\
\hline HEL13 & $182-192$ & 5 & 0.485 & 0.271 & 0.413 \\
\hline ILSTS005 & 183-189 & 4 & 0.473 & 0.454 & 0.375 \\
\hline ILSTS006 & $277-303$ & 12 & 0.723 & 0.639 & 0.686 \\
\hline INRA005 & $133-149$ & 8 & 0.737 & 0.767 & 0.689 \\
\hline INRA023 & $195-215$ & 11 & 0.802 & 0.795 & 0.770 \\
\hline INRA032 & $175-187$ & 7 & 0.707 & 0.655 & 0.658 \\
\hline INRA035 & $100-120$ & 6 & 0.674 & 0.174 & 0.610 \\
\hline INRA037 & $120-150$ & 11 & 0.826 & 0.771 & 0.803 \\
\hline INRA063 & $174-184$ & 5 & 0.708 & 0.653 & 0.652 \\
\hline MM12 & $106-128$ & 10 & 0.641 & 0.681 & 0.606 \\
\hline SPS115 & $246-258$ & 6 & 0.784 & 0.767 & 0.746 \\
\hline TGLA53 & $153-185$ & 16 & 0.893 & 0.846 & 0.880 \\
\hline TGLA122 & $129-181$ & 17 & 0.838 & 0.672 & 0.815 \\
\hline TGLA126 & $116-134$ & 8 & 0.804 & 0.746 & 0.772 \\
\hline TGLA227 & 77-109 & 15 & 0.852 & 0.725 & 0.833 \\
\hline Mean & & 9.20 & 0.733 & 0.667 & 0.691 \\
\hline SE & & 0.58 & 0.018 & 0.028 & 0.021 \\
\hline
\end{tabular}

TNA, total number of alleles per locus, across breeds; $\mathrm{H}_{\text {Exp }}$, expected heterozygosity frequency, average across breeds; $\mathrm{H}_{\mathrm{Obs}}$, observed heterozygosity frequency, average across breeds; PIC, polymorphism information content, average across breeds; SE, standard error.

are considered endangered breeds (IUCN, 2000). The $\mathrm{H}_{\text {Exp }}$ and $\mathrm{H}_{\mathrm{Obs}}$ values observed in $\mathrm{KNC}$ breeds are reportedly similar or higher than those of British and Spanish cattle

Table 2. Genetic diversity parameters estimated for 30 microsatellite loci in four Korean native cattle breeds

\begin{tabular}{lccccccc}
\hline Breed & $\mathrm{N}$ & $\mathrm{TNA}$ & $\mathrm{MNA}$ & $\mathrm{A}_{\mathrm{R}}$ & $\mathrm{H}_{\text {Exp }}$ & $\mathrm{H}_{\text {Obs }}$ & PIC \\
\hline Hanwoo & 30 & 209 & $6.97 \pm 0.41$ & $6.42 \pm 0.37$ & $0.713 \pm 0.025$ & $0.680 \pm 0.033$ & $0.665 \pm 0.026$ \\
Chikso & 30 & 200 & $6.67 \pm 0.39$ & $6.12 \pm 0.33$ & $0.708 \pm 0.023$ & $0.683 \pm 0.031$ & $0.654 \pm 0.024$ \\
Heugu & 30 & 142 & $4.73 \pm 0.32$ & $4.39 \pm 0.28$ & $0.619 \pm 0.025$ & $0.625 \pm 0.041$ & $0.554 \pm 0.027$ \\
Jeju black & 30 & 160 & $5.33 \pm 0.43$ & $4.91 \pm 0.37$ & $0.604 \pm 0.029$ & $0.613 \pm 0.034$ & $0.543 \pm 0.029$ \\
Total/mean & 120 & 276 & $5.93 \pm 0.53$ & $5.46 \pm 0.48$ & $0.661 \pm 0.029$ & $0.650 \pm 0.018$ & $0.604 \pm 0.032$ \\
\hline
\end{tabular}

$\mathrm{N}$, number of animals; TNA, total number of alleles with standard error; MNA, mean number of alleles with standard error; $\mathrm{A}_{\mathrm{R}}$, allelic richness with standard error; $\mathrm{H}_{\mathrm{Exp}}$, expected heterozygosity with standard error; $\mathrm{H}_{\mathrm{Obs}}$, observed heterozygosity with standard error; PIC, polymorphism information content with standard error. 
Table 3. Nei's genetic distance $\left(D_{A}\right)$ values among six cattle breeds. Maximum and minimum values are shown in bold

\begin{tabular}{lcccccc}
\hline & \multicolumn{6}{c}{ Breed } \\
\cline { 2 - 7 } & HW & CS & HU & JJ & HT & CR \\
\hline HW & - & & & & & \\
CS & $\mathbf{0 . 1 2 9}$ & - & & & & \\
HU & 0.185 & 0.193 & - & & & \\
JJ & 0.181 & 0.180 & 0.265 & - & & \\
HT & 0.239 & 0.227 & 0.311 & $\mathbf{0 . 3 1 6}$ & - & \\
CR & 0.194 & 0.193 & 0.274 & 0.255 & 0.188 & - \\
\hline
\end{tabular}

HW, Hanwoo; CS, Chikso; HU, Heugu; JJ, Jeju black; HT, Holstein; CR, Charolais.

breeds $\left(\mathrm{H}_{\mathrm{Exp}}=0.56\right.$ to 0.68 and $\mathrm{H}_{\mathrm{Obs}}=0.59$ to 0.67$)$ (Wiener et al., 2004; Martin-Burriel et al., 2007; Padilla et al., 2009). The mean values of $\mathrm{H}_{\mathrm{Obs}}$ in $\mathrm{HW}$ and CS breeds were lower than those of $\mathrm{H}_{\text {Exp }}$. Generally, the mating of the four $\mathrm{KNC}$ breeds has been non-randomly performed by using limited bulls. In addition, the number of bulls used is fewer in HW and CS than in HU and JB based on population size.

\section{Genetic distance and phylogenetic analysis}

To verify the genetic relationship among the four Korean native and two exotic cattle breeds, we calculated the $D_{A}$ distance and constructed a phylogenetic tree. Among the Korean native breeds, HW and CS were closest $\left(D_{A}=\right.$ 0.129 ), with the largest difference observed for JJ and HU $\left(D_{A}=0.265\right) \quad($ Table 3$)$. The phylogenetic tree was constructed from a neighbor joining (NJ) clustering based on the $D_{A}$ distance matrix among breeds (Figure 2). The genetic relationship between $\mathrm{HW}$ and CS was relatively

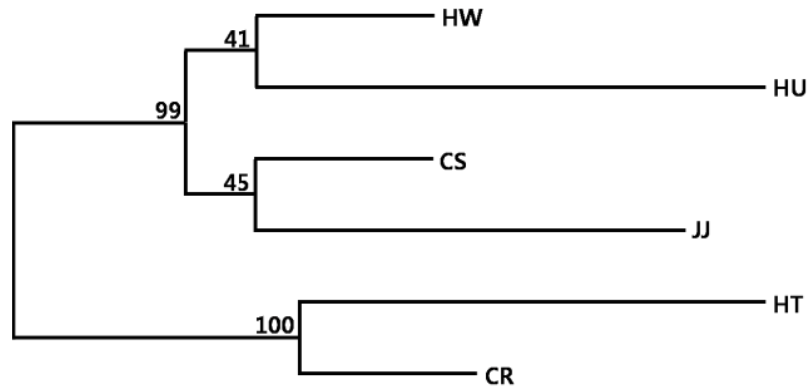

Figure 2. Phylogenetic tree constructed from $D_{A}$ by the neighborjoining method showing the genetic relationships among six cattle breeds. The values at the nodes are the percentages of bootstrap values from 1,000 replications of re-samplings. HW, Hanwoo; CS, Chikso; HU, Heugu; JJ, Jeju black; HT, Holstein; CR, Charolais.

close among the Korean breeds, whereas HU and JJ were distinctly separated. The NJ tree indicated a clear separation of two exotic breeds (HT, CR) from the four KNC breeds. Yoon et al. (2005) emphasized that genetic similarity was high among Hanwoo, Heugu, two Japanese breeds, and a Chinese breed (Yanbian). Additionally, the bootstrap values among these breeds ranged from 40 to 50. Thus, the low values in this study were caused by high genetic similarity among Korean native breeds.

The FCA analysis revealed the very clear separation between the HT, CR, HU, JJ, and other two Korean breeds (HW and CS) (Figure 3). About $75 \%$ of the variance was accounted for by the first to three dimensions of the FCA Axis 1 (33.33\% of total variance explained), which separated HT and CR from the Korean native breeds. Axis 2 (24.37\%) further separated HU, JJ and the HW and CS Korean breeds. Axis 3 (17.20\%) distinctly separated HT and

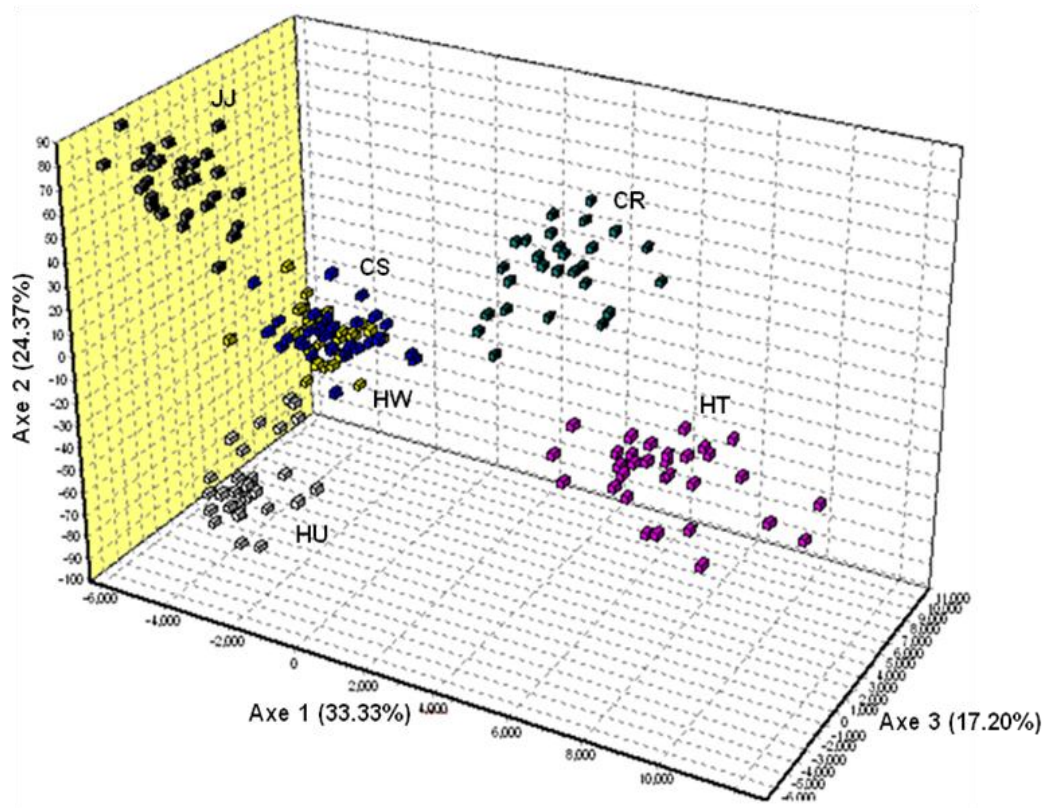

Figure 3. Factorial Correspondence Analysis of individual cattle microsatellite genotypes calculated using GENETIX. HW, Hanwoo; CS, Chikso; HU, Heugu; JJ, Jeju black; HT, Holstein; CR, Charolais. 


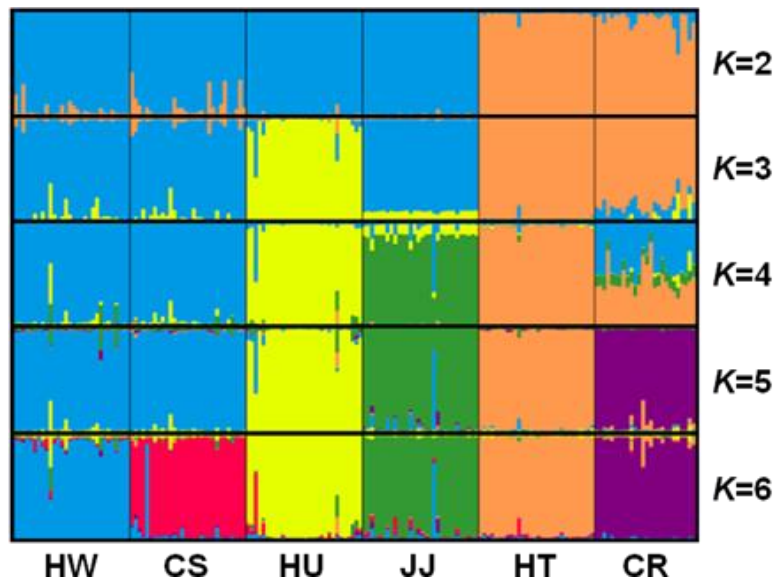

Figure 4. Population structure of the analyzed six cattle breeds without prior population affiliation using a model-based clustering method implemented in STRUCTURE for $K=2$ to $K=6$. Each column represents the proportion in which an individual belongs to a different coloured cluster. HW, Hanwoo; CS, Chikso; HU, Heugu; JJ, Jeju black; HT, Holstein; CR, Charolais.

CR. These results indicated that individuals from HW and CS were mixed, suggesting a closer relationship between them. $D_{A}$ distance, phylogenetic tree and FCA results provide genetic evidence for the differentiation of the four Korean cattle breeds.

\section{Bayesian identification of genetic clusters}

STRUCTURE software was used to determine the unbiased structure without prior knowledge regarding the number of breeds (Figure 4). At $K=2$, two main groups that accurately corresponded to Korean native and exotic cattle breeds were formed. As $K$ increased, the contributions of the assumed populations resulted in the progressively complete separation of the 6 breeds. The largest delta $K$ $(\Delta K)$ value was calculated as previously described (Evanno et al., 2005). The optimum $\Delta K$ value $(\Delta K=92.94$, data not shown) was found at $K=5$. These results failed to differentiate between the HW and CS breeds. However, each breed grouped in its own cluster with an estimated membership $>0.893$ at $K=6(\Delta K=52.54)$ (Figure 4, Table 4). According to Leroy et al. (2009), the highest $\Delta K$ values can potentially reveal the optimal $K$, but some weakly defined substructures can be found when only a small number or breeds are analyzed. In addition, Kim et al. (2013) suggested that CS and HW have a genetic difference based on sequence variation and phylogenetic analysis of mtDNA $c y t$ b gene. Based on these reports, we considered that $\mathrm{HW}$ and $\mathrm{CS}$ could have distinct genetic characteristics.

In this study, the level of genetic diversity among KNC breeds differed according to their population sizes (endangered, vulnerable or not at risk). However, these were higher than those of several native cattle breeds of other countries. In analyses of genetic relationship and clustering, all KNC breeds were genetically differentiated from the two exotic breeds. In addition, the scientific evidence supports the genetic differentiation among four KNC breeds. The results suggest that each KNC breed had distinct breed-specific genetic characteristics. The results of this study may be useful as scientific evidence to design plans for future conservation, improvement and breed management of each KNC breed.

\section{ACKNOWLEDGMENTS}

This work was carried out with the support of "Cooperative Research Program for Agriculture Science and Technology Development (Project title: Molecular genetic monitoring of conservation population of animal genetic resources, Project No. PJ008431)" Rural Development Administration, Republic of Korea. This study was supported by 2014 Postdoctoral Fellowship Program of National Institute of Animal Science, Rural Development Administration, Republic of Korea.

\section{REFERENCES}

Acosta, A. C., O. Uffo, A. Sanz, R. Ronda, R. Osta, C. Rodellar, I. Martin-Burriel, and P. Zaragoza. 2013. Genetic diversity and differentiation of five Cuban cattle breeds using 30 microsatellite loci. J. Anim. Breed. Genet. 130:79-86.

Belkhir, K., P. Borsa, L. Chikhi, N. Raufaste, and F. Bonhomme. 2004. GENETIX ver. 4.05, Logiciel sous WindowsTM pour la

Table 4. Population of membership of each the six cattle population genotypes with the ISAG/FAO recommended 30 microsatellite markers in the six inferred clusters using STRUCTURE analysis

\begin{tabular}{lccccccc}
\hline \multirow{2}{*}{ Breed } & \multicolumn{9}{c}{ Inferred clusters } & \multicolumn{2}{c}{$\begin{array}{c}\text { Number of } \\
\text { Individuals }\end{array}$} \\
\cline { 2 - 6 } & 1 & 2 & 3 & 4 & 5 & 6 & 30 \\
HW & $\mathbf{0 . 9 1 4}$ & 0.010 & 0.022 & 0.005 & 0.023 & 0.026 & 30 \\
CS & 0.060 & 0.010 & $\mathbf{0 . 8 9 3}$ & 0.008 & 0.013 & 0.016 & 30 \\
HU & 0.011 & 0.005 & 0.035 & 0.009 & 0.019 & $\mathbf{0 . 9 2 1}$ & 30 \\
JJ & 0.043 & 0.013 & 0.022 & 0.005 & $\mathbf{0 . 9 1 0}$ & 0.007 & 30 \\
HT & 0.008 & 0.008 & 0.014 & $\mathbf{0 . 9 5 8}$ & 0.005 & 0.007 & 26 \\
CR & 0.010 & $\mathbf{0 . 9 3 4}$ & 0.009 & 0.032 & 0.006 & 0.010 & \\
\hline
\end{tabular}

ISAG/FAO, International Society for Animal Genetics/Food and Agriculture Organization; HW, Hanwoo; CS, Chikso; HU, Heugu; JJ, Jeju black; HT, Holstein; CR, Charolais. 
Génétique des Populations. Laboratoire Génome et Population, Université Montpellier II, Montpellier, France. http://kimura.univ-montp2.fr/genetix/ Accessed May 30, 2014.

Botstein, D., R. L. White, M. Skolnick, and R. W. Davis. 1980 Construction of a genetic linkage map in man using restriction fragment length polymorphisms. Am. J. Hum. Genet. 32:314331.

Choi, T. J., S. S. Lee, D. H. Yoon, H. S. Kang, C. D. Kim, I. H. Hwang, C. Y. Kim, X. Jin, C. G. Yang, and K. S. Seo. 2012. Determination of genetic diversity among Korean Hanwoo cattle based on physical characteristics. Asian Australas. J. Anim. Sci. 25:1205-1215.

Dadi, H., M. Tibbo, Y. Takahashi, K. Nomura, H. Hanada, and T. Amano. 2008. Microsatellite analysis reveals high genetic diversity but low genetic structure in Ethiopian indigenous cattle populations. Anim. Genet. 39:425-431.

Dieringer, D. and C. Schlötterer. 2003. Microsatellite analyzer (MSA): A platform independent analysis tool for large microsatellite data sets. Mol. Ecol. Notes 3:167-169.

Earl, D. A. and B. M. vonHoldt. 2012. STRUCTURE HARVESTER: A website and program for visualizing STRUCTURE output and implementing the Evanno method. Conserv. Genet. Resour. 4:359-361.

Egito, A. A., S. R. Paiva, Maria do Socorro M. Albuquerque, A. S. Mariante, L. D. Almeida, S. R. Castro, and D. Grattapaglia. 2007. Microsatellite based genetic diversity and relationships among ten Creole and commercial cattle breeds raised in Brazil. BMC Genet. 8:83.

Evanno, G., S. Regnaut, and J. Goudet. 2005. Detecting the number of clusters of individuals using the software STRUCTURE: A simulation study. Mol. Ecol. 14: 2611-2620.

Goudet, J. 2002. FSTAT version 2.9.3.2. department of ecology and evolution, University of Lausanne, Swizeland.

Groeneveld, L. F., J. A. Lenstra, H. Eding, M. A. Toro, B. Scherf, D. Pilling, R. Negrini, E. K. Finlay, H. Jianlin, E. Groeneveld, and S. Weigend. 2010. Genetic diversity in farm animals-A review. Anim. Genet. 41: 6-31.

Hoffmann, I., P. A. Marsan, J. S. F. Barker, E. G. Cothran, O. Hanotte, J. A. Lenstra, D. Milan, S. Weigend, and H. Simianer. 2004. New MoDAD marker sets to be used in diversity studies for the major farm animal species: recommendations of a joint ISAG/FAO working group. Proceedings of the 29th International Conference on Animal Genetics. Toyko, Japan. pp. 11-16.

IUCN (International Union for Conservation of Nature). 2000. The IUCN Red List Categories and Criteria Version 3.1. Gland, Switzerland.

Jakobsson, M. and N. A. Rosenberg. 2007. CLUMPP: A cluster matching and permutation program for dealing with label switching and multimodality in analysis of population structure. Bioinformatics 23:1801-1806.

Kalinowski, S. T., M. L. Taper, and T. C. Marshall. 2007. Revising how the computer program CERVUS accommodates genotyping error increases success in paternity assignment. Mol. Ecol. 16:1099-1106.

Kim, J. B. and C. Lee. 2000. Historical look at the genetic improvement in Korean cattle - Review -. Asian Australas. J. Anim. Sci. 13:1467-1481.
Kim, J. H., M. J. Byun, M. J. Kim, S. W. Suh, Y. G. Ko, C. W. Lee, K. S. Jung, E. S. Kim, D. J. Yu, W. Y. Kim, and S. B. Choi. 2013. mtDNA diversity and phylogenetic state of Korean cattle breed, Chikso. Asian Australas. J. Anim. Sci. 26:163-170.

Kim, K. S., J. S. Yeo, and C. B. Choi. 2002. Genetic diversity of north-east Asian cattle based on microsatellite data. Anim. Genet. 33:201-204.

Leroy, G., E. Verrier, J. C. Meriaux, and X. Rognon. 2009. Genetic diversity of dog breeds: between-breed diversity, breed assignation and conservation approaches. Anim. Genet. 40:333-343.

MAF (Ministry of Agriculture and Forestry, Republic of Korea). 2004. National Report on the State of Animal Genetic Resources. Seoul, Rep of Korea. p. 20-21. $\mathrm{ftp} / / / \mathrm{ftp}$.fao.org/docrep/fao/010/a1250e/annexes/CountryRepor ts/KoreanRepublic.pdf/ Accessed May 30, 2014.

Martin-Burriel, I., C. Rodellar, J. A. Lenstra, A. Sanz, C. Cons, R. Osta, M. Reta, S. D. Argüello, S. Sanz, and P. Zaragoza. 2007. Genetic diversity and relationships of endangered Spanish cattle breeds. J. Hered. 98:687-691.

Maudet, C., G. Luikart, and P. Taberlet. 2002. Genetic diversity and assignment tests among seven French cattle breeds based on microsatellite DNA analysis. J. Anim. Sci. 80:942-950.

Na, G. J. 2008. Characteristics of Korean native cattle (in Korean). Korea Animal Improvement Association Bulletin 1:42-52.

Nei, M., F. Tajima, and Y. Tateno. 1983. Accuracy of estimated phylogenetic trees from molecular data. J. Mol. Evol. 19:153170

Padilla, J. Á., E. Sansinforiano, J. C. Parejo, A. Rabasco, and M. Martínez-Trancón. 2009. Inference of admixture in the endangered Blanca Cacereña bovine breed by microsatellite analyses. Livest. Sci. 122:314-322.

Pham, L. D., D. N. Do, N. T. Binh, L. Q. Nam, N. V. Ba, T. T. T. Thuy, T. X. Hoan, V. C. Cuong, and H. N. Kadarmideen. 2013. Assessment of genetic diversity and population structure of Vietnamese indigenous cattle populations by microsatellites. Livest. Sci. 155:17-22.

Pritchard, J. K., M. Stephens, and P. Donnelly. 2000. Inference of population structure using multilocus genotype data. Genetics 155:945-959.

Rosenberg, N. A. 2004. DISTRUCT: A program for the graphical display of population structure. Mol. Ecol. Notes 4:137-138.

Wiener, P., D. Burton, and J. L. Williams. 2004. Breed relationships and definition in British cattle: A genetic analysis. Heredity 93:597-602.

Yoon, D. H., E. W. Park, S. H. Lee, H. K. Lee, S. J. Oh, I. C. Cheong, and K. C. Hong. 2005. Assessment of genetic diversity and relationships between Korean cattle and other cattle breeds by microsatellite loci. J. Anim. Sci. Technol. (Kor.) 47:341-354

Zhang, G. X., Z. G. Wang, W. S. Chen, C. X. Wu, X. Han, H. Chang, L. S. Zan, R. L. Li, J. H. Wang, W. T. Song, G. F. Xu, H. J. Yang, and Y. F. Luo. 2007. Genetic diversity and population structure of indigenous yellow cattle breeds of China using 30 microsatellite markers. Anim. Genet. 38:550-559. 